\title{
A Re-Analysis of Historical Los Alamos Critical Assembly Reaction Rate Measurements
}

\author{
A.C. Kahler ${ }^{\mathrm{a}}$, M. MacInnes, and M.B. Chadwick \\ Los Alamos National Laboratory, Los Alamos, NM 87545, USA
}

\begin{abstract}
Starting in the 1950s and continuing into the early 1970s, a number of foil irradiations and fission chamber measurements were made in a variety of Fast critical assemblies at Los Alamos National Laboratory. These include (i) Godiva, a bare HEU spherical assembly; (ii) Flattop-25, a spherical assembly consisting of an HEU core and a natural uranium reflector; (iii) Jezebel, a bare ${ }^{239} \mathrm{Pu}$ assembly; and (iv) Flattop-Pu, a spherical assembly consisting of a ${ }^{239} \mathrm{Pu}$ core and a natural uranium reflector. In most instances the irradiations occur at or near the center of the assembly, but in selected instances data were obtained for a radial traverse extending into the Flattop reflector region. Measurements were made for a number of threshold reactions, including ${ }^{45} \mathrm{Sc}(\mathrm{n}, 2 \mathrm{n}){ }^{44 \mathrm{~m}} \mathrm{Sc},{ }^{51} \mathrm{~V}(\mathrm{n}, \alpha){ }^{48} \mathrm{Sc},{ }^{75} \mathrm{As}(\mathrm{n}, 2 \mathrm{n}){ }^{74} \mathrm{As}$, ${ }^{89} \mathrm{Y}(\mathrm{n}, 2 \mathrm{n})^{88} \mathrm{Y},{ }^{90} \mathrm{Zr}(\mathrm{n}, 2 \mathrm{n}){ }^{89} \mathrm{Zr},{ }^{103} \mathrm{Rh}(\mathrm{n}, 2 \mathrm{n}){ }^{102 g} \mathrm{Rh},{ }^{107} \mathrm{Ag}(\mathrm{n}, 2 \mathrm{n}){ }^{106 \mathrm{~m}} \mathrm{Ag},{ }^{169} \mathrm{Tm}(\mathrm{n}, 2 \mathrm{n}){ }^{168} \mathrm{Tm}$, ${ }^{175} \mathrm{Lu}(\mathrm{n}, 2 \mathrm{n}){ }^{174} \mathrm{Lu},{ }^{191} \mathrm{Ir}(\mathrm{n}, 2 \mathrm{n}){ }^{190} \mathrm{Ir},{ }^{197} \mathrm{Au}(\mathrm{n}, 2 \mathrm{n}){ }^{196} \mathrm{Au},{ }^{203} \mathrm{Tl}(\mathrm{n}, 2 \mathrm{n}){ }^{202} \mathrm{Tl},{ }^{204} \mathrm{~Pb}(\mathrm{n}, 2 \mathrm{n}){ }^{203} \mathrm{~Pb}$ and ${ }^{238} \mathrm{U}(\mathrm{n}, 2 \mathrm{n}){ }^{237} \mathrm{U}$. Fission ratio data for ${ }^{238} \mathrm{U}(\mathrm{n}, \mathrm{f}) /{ }^{235} \mathrm{U}(\mathrm{n}, \mathrm{f})$ and ${ }^{239} \mathrm{Pu}(\mathrm{n}, \mathrm{f}) /{ }^{235} \mathrm{U}(\mathrm{n}, \mathrm{f})$ were also obtained. We report C/E values from MCNP6 calculations using ENDF/B-VII.1 and IRDFF-v1.03 cross section data.
\end{abstract}

\section{Introduction}

We compare predicted versus measured reaction rate spectral indices for a variety of threshold reactions in the Los Alamos Godiva, Jezebel, Flattop-25 \& -Pu and Big-10 critical assemblies. Godiva is a bare sphere of highly-enriched ${ }^{235} \mathrm{U}$ (HEU), Jezebel is a bare sphere of $\sim 95$ weight per cent ${ }^{239} \mathrm{Pu}$, the Flattop assemblies contain either an HEU or a ${ }^{239} \mathrm{Pu}$ core surrounded by a thick ${ }^{\text {nat }} \mathrm{U}$ reflector and Big-10 is a large heterogeneous uranium cylinder whose average enrichment is $10 \%$. The benchmark models used in these calculations are defined in the International Criticality Safety Benchmark Evaluation Project (ICSBEP) Handbook [1]. Note that the Jezebel benchmark, Pu-MET-FAST-001 in ICSBEP nomenclature, was recently re-evaluated. The results presented here are obtained with this new benchmark model. The comparisons to experiment focus on ENDF/B-VII.1 cross sections [2], but the recently released IAEA's IRDFF-v1.03 [3] are also used in a few cases.

\footnotetext{
${ }^{\text {a }}$ Corresponding author: akahler@lanl.gov
}

This is an Open Access article distributed under the terms of the Creative Commons Attribution License 2.0, which permits unrestricted use, distribution, and reproduction in any medium, provided the original work is properly cited. 
Table 1. A Selection of LANL Irradiation Measurements.

\begin{tabular}{|c|c|c|}
\hline Assembly & Irradiation Date & ICSBEP Benchmark \\
\hline Godiva & $6 / 30 / 1959$ & HEU-MET-FAST-001 (rev 2) \\
\hline & $3 / 5 / 1962$ & \\
Flattop-25 & $3 / 30 / 1962$ & HEU-MET-FAST-028 (rev 1) \\
& $4 / 29 / 1968$ & \\
& $4 / 7 / 1969$ & \\
\hline Jezebel & $10 / 23 / 1973$ & Pu-MET-FAST-001 (rev 3) \\
\hline & $3 / 25 / 1962$ & \\
Flattop-Pu & $8 / 5 / 1963$ & Pu-MET-FAST-006 (rev 1) \\
& $8 / 10 / 1967$ & \\
\hline Big-10 & $8 / 5 / 1970$ & \\
\hline
\end{tabular}

Table 2. Selected 14.1 MeV Cross Section Data (barns).

\begin{tabular}{|c|c|c|c|}
\hline Reaction & Pre-1963 & Post-1963 & ENDF/B-VII.1 \\
\hline${ }^{51} \mathrm{~V}(\mathrm{n}, \alpha)^{48} \mathrm{Sc}$ & 0.0157 & & 0.0152 \\
\hline${ }^{90} \mathrm{Zr}(\mathrm{n}, 2 \mathrm{n})^{89} \mathrm{Zr}$ & 0.643 & 0.590 & 0.617 \\
\hline${ }^{103} \mathrm{Rh}(\mathrm{n}, 2 \mathrm{n}){ }^{102 \mathrm{~m}} \mathrm{Rh}$ & 0.750 & 0.783 & 0.741 \\
\hline${ }^{169} \mathrm{Tm}(\mathrm{n}, 2 \mathrm{n})^{168} \mathrm{Tm}$ & & 1.96 & 1.980 \\
\hline${ }^{197} \mathrm{Au}(\mathrm{n}, 2 \mathrm{n})^{196} \mathrm{Au}$ & & 2.214 & 2.132 \\
\hline${ }^{203} \mathrm{Tl}(\mathrm{n}, 2 \mathrm{n})^{202} \mathrm{Tl}$ & 1.428 & 2.090 & 2.005 \\
\hline${ }^{204} \mathrm{~Pb}(\mathrm{n}, 2 \mathrm{n})^{203} \mathrm{~Pb}$ & 1.746 & & 2.193 \\
\hline${ }^{238} \mathrm{U}(\mathrm{n}, 2 \mathrm{n})^{237} \mathrm{U}$ & & 0.895 & 0.850 \\
\hline
\end{tabular}

\section{Discussion}

Irradiation measurements were made over a period of years, from the mid-1950s through early 1970s in various LANL critical assemblies. Table 1 summarizes the irradiation date for the experiments that are discussed in this report. We also note the ICSBEP benchmark evaluation used in our calculations. The reader is directed to Reference 1 for further information on these assemblies.

Most of the measurements occur at or near the center of the assembly, but in selected cases data were obtained for a radial traverse starting near the Flattop assembly center and extending into the radial reflector. Comparison of calculation-to-experiment in these cases, several examples of which are shown below, provides a test of the nuclear data over a wide energy range.

An important aspect of this re-analysis is the recognition that the results provided in the original reports depend upon the "known" nuclear data of the time, specifically the $14.1 \mathrm{MeV}$ cross section for the reaction of interest. That data may have changed significantly over the years. We show several examples of this in Table 2.

The MCNP6 [4] Monte Carlo program was used for the benchmark calculations. Results were obtained by combining results from ten independent 500-million history jobs (run as 100,000 histories per cycle times 5,000 cycles with the first 25 cycles discarded). F4 tallies were obtained for the relevant cross sections over a central $0.25 \mathrm{~cm}$ radius sphere, or for successive $0.5 \mathrm{~cm}$ thick shells. Results for each cross section of interest were divided by the ${ }^{235} \mathrm{U}(\mathrm{n}, \mathrm{f})$ tally in that region in order to produce a calculated spectral index. For this large number of histories, the stochastic uncertainty is smaller than the plot symbol and therefore no calculation error bars will appear in the figures that follow. In many cases, we also include a tally definition with "DEn" and "DFn" tally modifier cards that define a $\mathrm{f}(\mathrm{E})=\mathrm{E}$ function. Division of the original tally by the modified tally yields the average energy for that tally. Figure 1 illustrates the average flux as a function of radius for these assemblies. 


\section{$15^{\text {th }}$ ISRD}

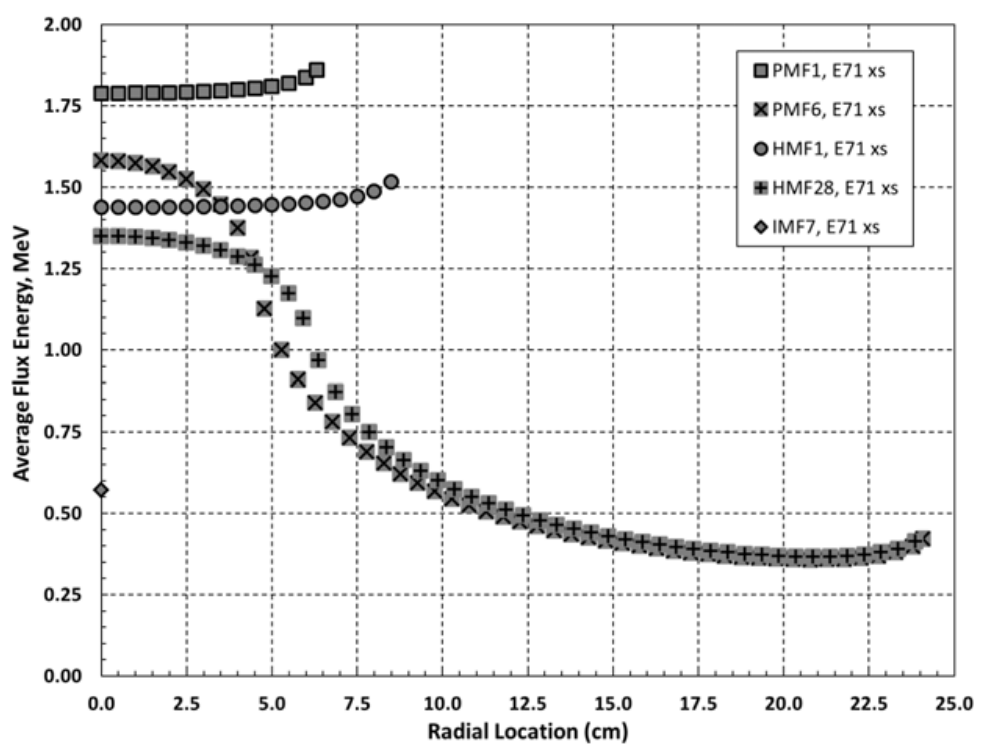

Figure 1. Average flux energy in $\mathrm{MeV}$ as a function of radius for the LANL Godiva (HMF1), Jezebel (PMF1), Flattop-25 (HMF28), Flattop-Pu (PMF6) and Big-10 (IMF7) critical assemblies. The Big-10 tally region corresponds to a $1-\mathrm{cm}$ diameter sphere at the measurement location and for display purposes is arbitrarily positioned at $\mathrm{r}=0$. "E71 xs" in the legend refers to ENDF/B-VII.1 cross section data.

Of course, the simple average energy noted above does not fully characterize the spectrum. We show in Fig. 2 the Flattop-25 spectrum near the core center and in the reflector. Also shown are cumulative spectrum curves, using the right hand axis, demonstrating that a broad energy distribution is incident upon the foils and fission counters.

Figures 3 and 4 illustrate $\mathrm{C} / \mathrm{E}$ values for a number of reactions, spanning an energy range from near 1.5 MeV to about $11 \mathrm{MeV}$ for Flattop-Pu and in excess of $14 \mathrm{MeV}$ for Flattop-25. Error bars here and in subsequent figures represent one sigma uncertainties and include estimates of experimental and cross section uncertainty. Uncertainty in the prompt fission spectrum is not included.

Results for the $\mathrm{Pu}$ fueled assemblies show excellent, near unity, $\mathrm{C} / \mathrm{E}$ values for the actinide $\left({ }^{238} \mathrm{U}\right.$, ${ }^{237} \mathrm{~Np}$ and ${ }^{239} \mathrm{Pu}$ ) fission reaction spectral indices but tend to be biased high for the suite of $(\mathrm{n}, 2 \mathrm{n})$ reaction spectral indices whose average energy is approximately $8 \mathrm{MeV}$ or more. For the HEU assemblies we again observe excellent $\mathrm{C} / \mathrm{E}$ values at the lower energies and this good agreement also extends into the higher energy regime.

In Fig. 5 we show $\mathrm{C} / \mathrm{E}$ values for the Big-10 critical assembly. The data points in this figure, from right-to-left correspond to the top-to-bottom list in the figure Legend. These results exhibit much greater scatter than those from the hotter HEU and Pu assemblies. For most of these reactions we also have used the recently released IRDFF-v1.03 cross section library. The ENDF/B-VII.1 based calculations and the IRDFF-v1.03 based calculations are generally consistent, although in some instances the differences are large enough to warrant a closer review of the underlying cross section evaluation.

Measurements for a radial traverse through the Flattop-25 core region and into the reflector are presented in Figs. 6 and 7. The basic transport calculation continues to be performed with ENDF/BVII.1 cross sections, but we include tally results based upon both the ENDF/B-VII.1 library and the IRDFF-v1.03 library. The general shape in the measured data is reproduced in these calculations, but there are issues that require further investigation. Note that in these figures, the horizontal "error bar" denotes the size and location of the tally region shell in the MCNP calculation. Uncertainties on these 


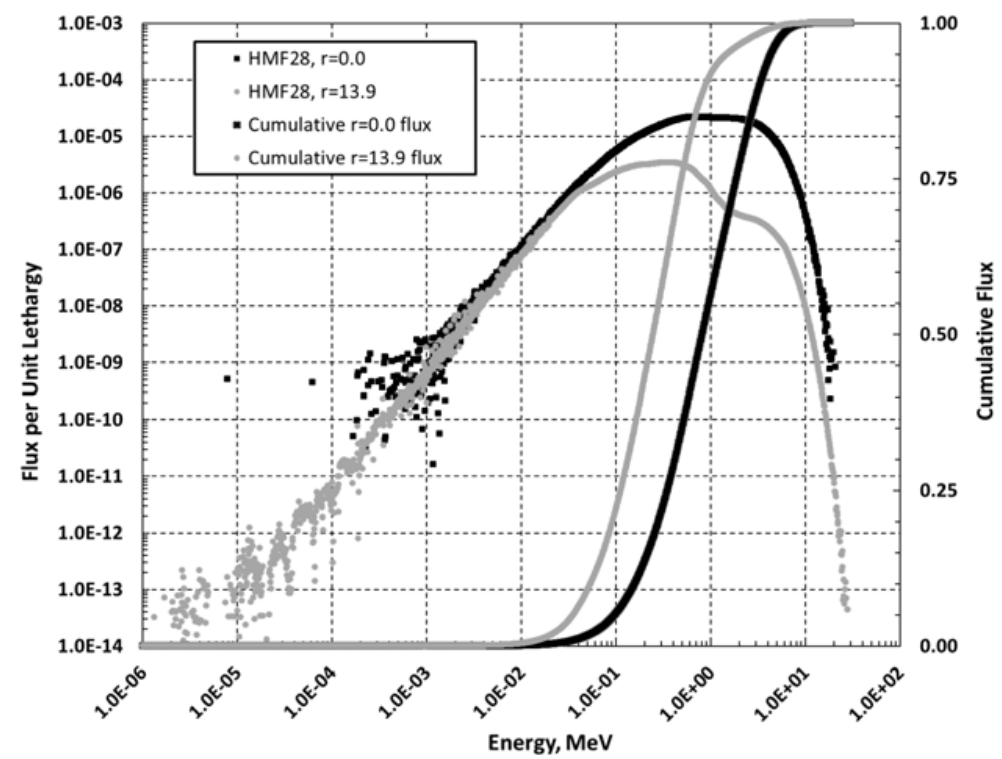

Figure 2. Flux energy distribution in Flattop-25. Calculated flux spectra near the core center and in the radial reflector are shown. Clearly a broad distribution of neutron energies is incident upon the fission counters and foils.

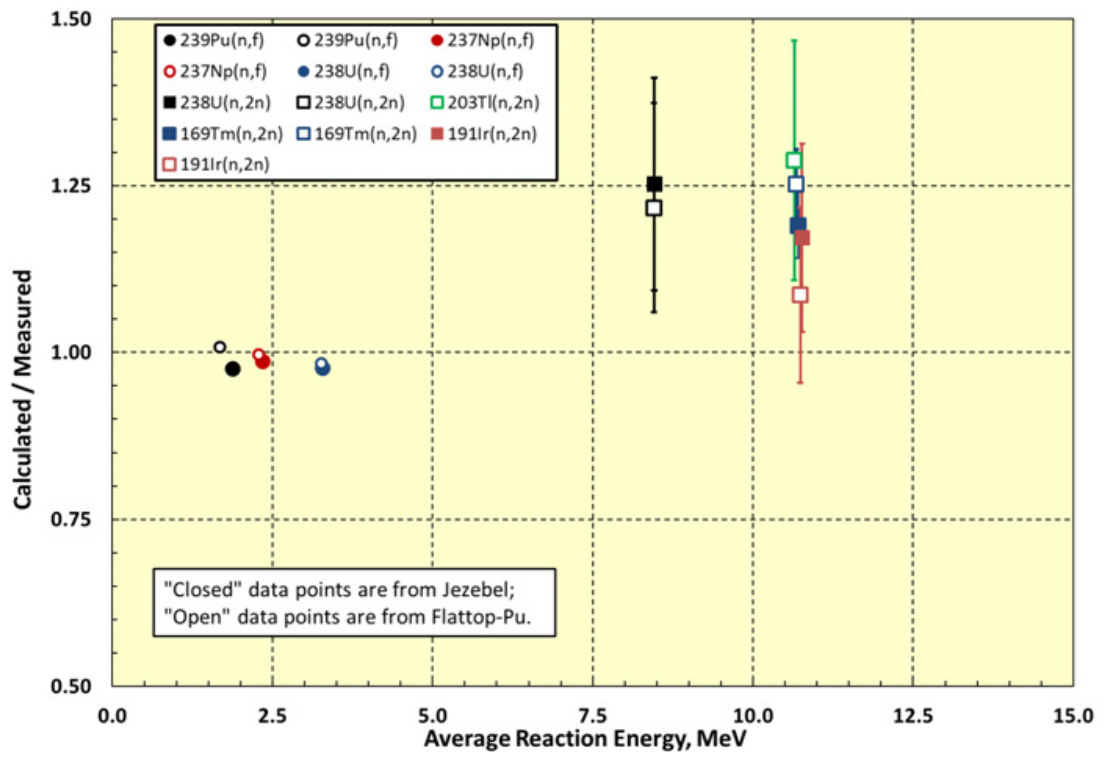

Figure 3. $\mathrm{C} / \mathrm{E}$ values for various spectral indices in the Pu fueled Jezebel and Flattop-Pu Critical Assemblies. MCNP6 calculations used ENDF/B-VII.1 cross sections.

radial traverse measured data have not been re-evaluated but are judged to be similar to those shown on Figs. 3 and 4 for central region measurements.

For the ${ }^{238} \mathrm{U}(\mathrm{n}, 2 \mathrm{n})$ reaction there is an obvious difference in the magnitude of the calculated spectral indices. The fluctuations in the data make it difficult to select one result over the other but we note that 


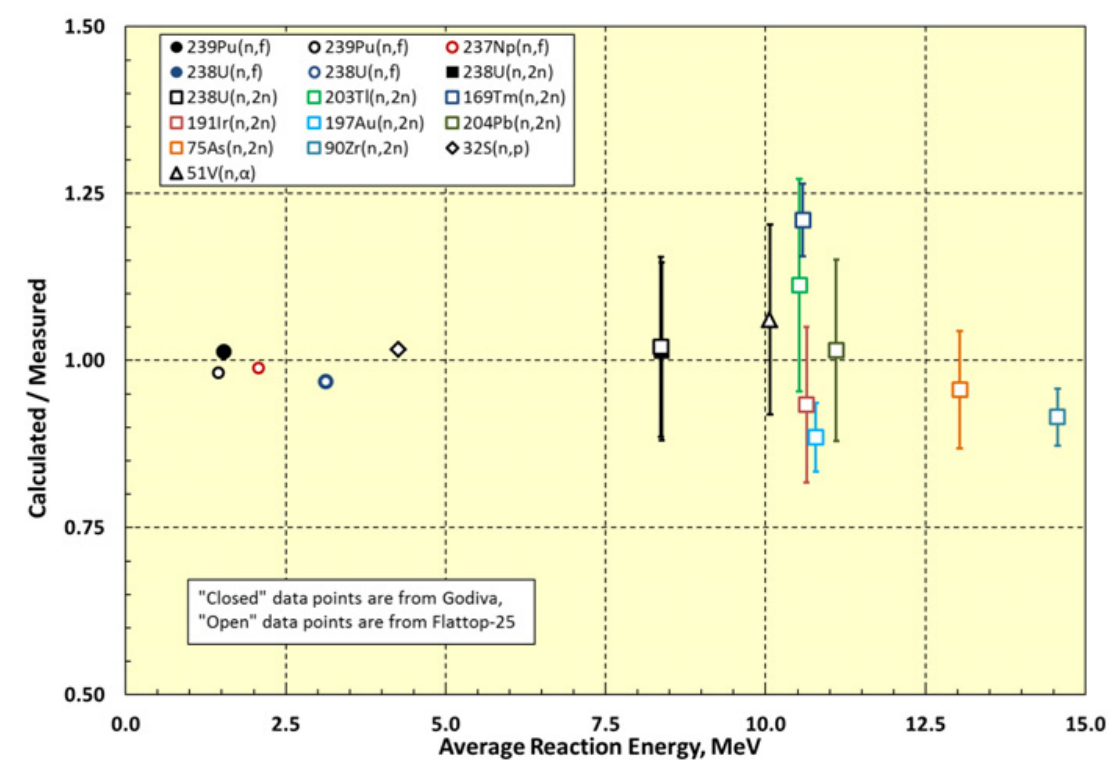

Figure 4. C/E values for various spectral indices in the HEU fueled Godiva and Flattop-25 Critical Assemblies. MCNP6 calculations used ENDF/B-VII.1 cross sections.

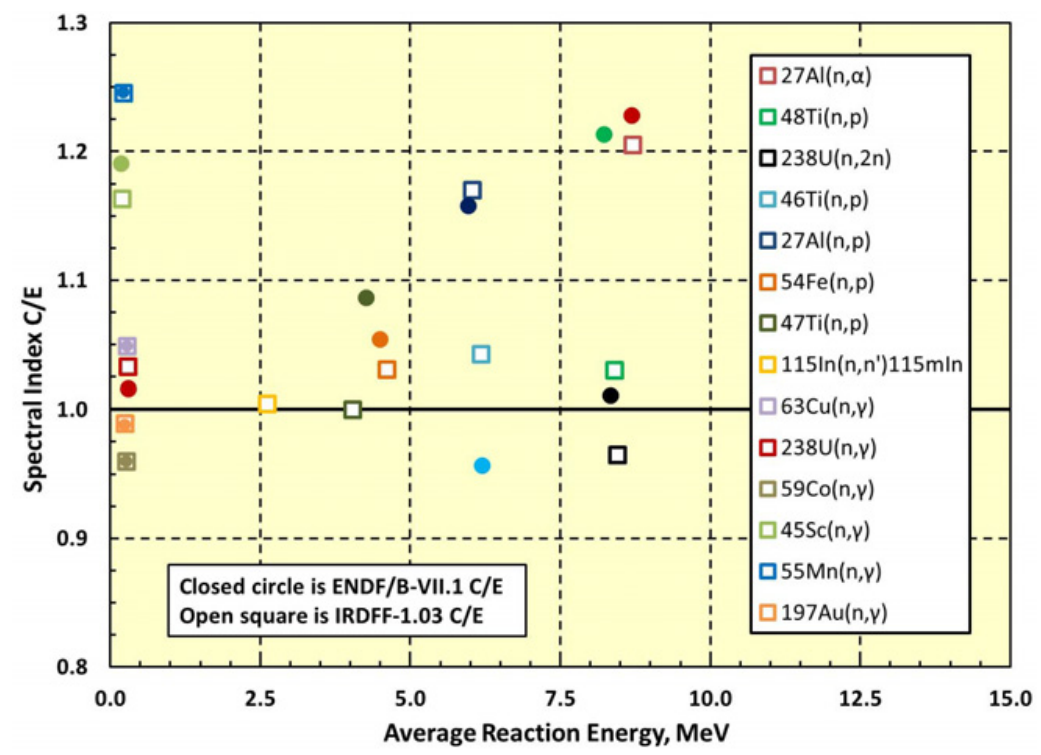

Figure 5. C/E values for various spectral indices in the Big-10 Assembly.

in Fig. 5 where a similar difference is observed that the ENDF/B-VII.1 based calculation's C/E is closer to unity. For ${ }^{90} \mathrm{Zr}(\mathrm{n}, 2 \mathrm{n})$ the ENDF/B-VII.1 and IRDFF-v1.03 calculations are in closer agreement but clearly biased low compared to measurement. This result, also seen in the highest energy result in Fig. 4 is consistent throughout the radial traverse. 


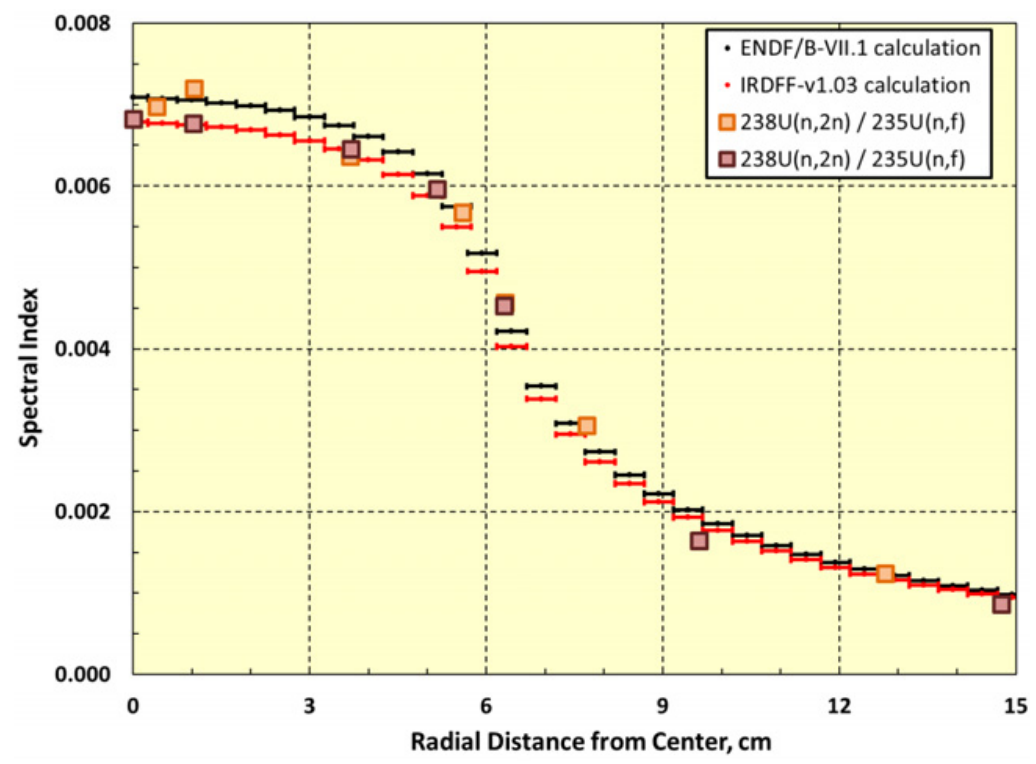

Figure 6. Measured and Calculated Spectral Indices for the ${ }^{238} U(n, 2 n)$ reaction for a radial traverse in the Flattop-25 Critical Assembly. Calculated values with the IRDFF-v1.03 cross section are consistently less than those obtained with ENDF/B-VII.1 cross sections.

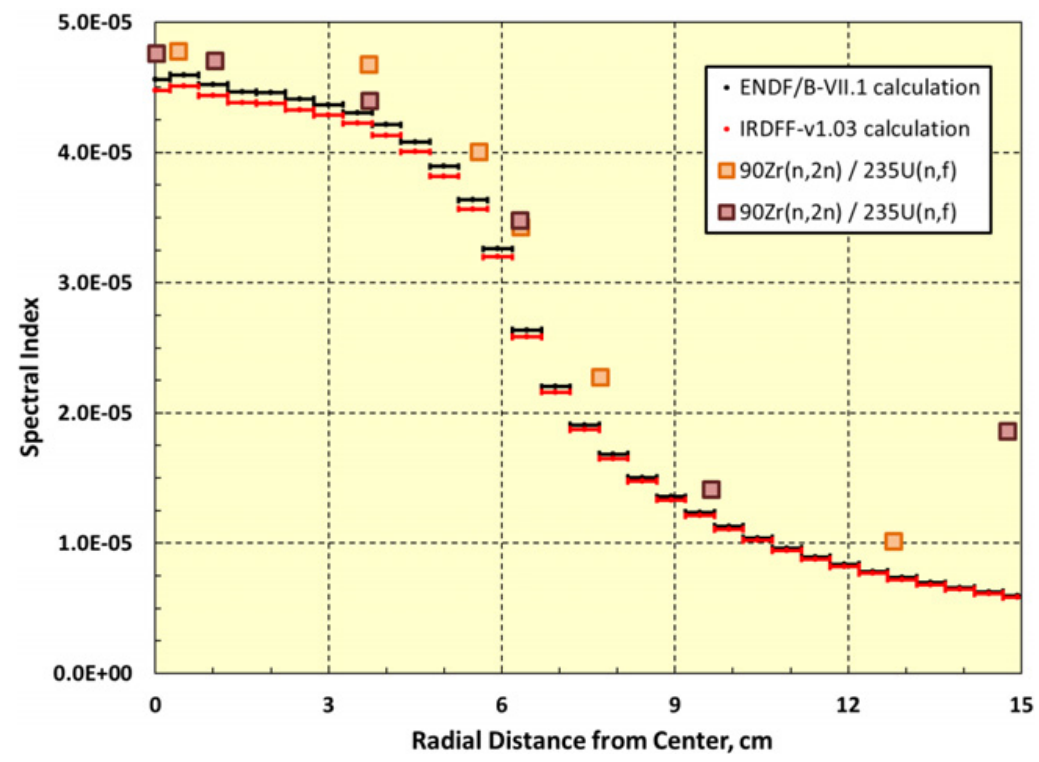

Figure 7. Measured and Calculated Spectral Indices for the ${ }^{90} \mathrm{Zr}(\mathrm{n}, 2 \mathrm{n})$ reaction for a radial traverse in the Flattop25 Critical Assembly. Calculated values with ENDF/B-VII.1 and IRDFF-v1.03 cross section are similar but consistently biased low compared to measurement. The measured data near $15 \mathrm{MeV}$ appears anomalous, as the reported value in Table 10 of [5] is more than twice as great as the measured $13 \mathrm{MeV}$ value. 


$$
15^{\text {th }} \text { ISRD }
$$

\section{Final Observations}

In this report we have provided a summary of some of the many spectral index measurements made in the Los Alamos Godiva, Jezebel, Flattop-25 \& -Pu and Big-10 critical assemblies. These measurements represent an important data set for cross section and prompt fission neutron spectrum testing. We note that when utilizing data from older measurements it is important to fully understand the methods, assumptions and perhaps most important, the underlying nuclear data knowledge of the time so that comparisons with today's knowledge are properly normalized.

Surprisingly large differences continue to exist in modern nuclear data evaluated files. The figures that include both ENDF/B-VII.1 and IRDFF-v1.03 provide several examples, but such differences are commonly seen when evaluated files from the European and Japanese communities (i.e., the JEFF-3.x and JENDL-4.x libraries) are compared. Resolving these differences remains a work-in-progress [6].

\section{References}

[1] J.B. Briggs, editor, International Handbook of Evaluated Criticality Safety Benchmark Experiments. NEA No. 7166, September 2013

[2] M.B. Chadwick et al., "ENDF/B-VII.1 Nuclear Data for Science and Technology: Cross Sections, Covariances, Fission Product Yields and Decay Data," Nuclear Data Sheets 112/12 (2011), 2887

[3] A. Trkov, coordinator, International Reactor Dosimetry and Fusion File, IRDFF. Available at https://www-nds.iaea.org/IRDFF/

[4] J.T. Goorley, "Initial MCNP6 Release Overview," LA-UR-11-07082, Los Alamos National Laboratory. Also Nuclear Technology 180 (2012), 298

[5] C.I. Browne, "Radiochemical Experiments on the Flattop Assembly," Los Alamos Scientific Laboratory memorandum J-11, dated March 7, 1962

[6] M.B. Chadwick et al., "The CIELO Collaboration: Neutron Reactions on ${ }^{1} \mathrm{H},{ }^{16} \mathrm{O},{ }^{56} \mathrm{Fe},{ }^{235,238} \mathrm{U}$ and ${ }^{239}$ Pu," Nuclear Data Sheets 118 (2014), 1 